\title{
Secondary School Mathematics Teachers' Instructional Practices in the Integration of Mathematics Analysis Software (MAS)
}

\author{
Mailizar Mailizar ${ }^{1 *}$ (D) , Lianghuo Fan ${ }^{2,3}$ (D)
}

\begin{abstract}
${ }^{1}$ Mathematics Education Department, Universitas Syiah Kuala, Banda Aceh, INDONESIA
${ }^{2}$ Asian Centre for Mathematics Education, East China Normal University, Shanghai, CHINA

${ }^{3}$ Southampton Education School, University of Southampton, Southampton, UK

*Corresponding Author: mailizar@unsyiah.ac.id
\end{abstract}

Citation: Mailizar, M., \& Fan, L. (2021). Secondary School Mathematics Teachers' Instructional Practices in the Integration of Mathematics Analysis Software (MAS). International Electronic Journal of Mathematics Education, 16(1), em0618. https://doi.org/10.29333/iejme/9293

ARTICLE INFO

Received: 6 Jun. 2020

Accepted: 17 Sep. 2020

\begin{abstract}
This study aimed to examine mathematics teachers' integration of Mathematics Analysis Software (MAS) in the teaching of mathematics at upper secondary school classrooms. It employed a qualitative approach with classroom observations and interviews for the data collection. The study was carried out in Indonesia, and the participants were ten mathematics teachers from ten secondary schools. The finding suggested that the participants failed to take advantage of pedagogical opportunities to digital technology in facilitating students' knowledge construction. In addition, this study revealed that the instructional practices with technology at classroom and subject levels were closely related to the type of tasks they set in their lessons. Moreover, the findings indicate that it is important for mathematics teachers to set technology-rich mathematics tasks for students to fully capitalized pedagogical opportunities of Mathematics Analysis Software.
\end{abstract}

Keywords: mathematical analysis software, technology in mathematics education, teacher instructional practice, digital technology in mathematics teaching

\section{INTRODUCTION}

In the last decade, the number and variety of digital technology tools for mathematics classroom that students and teachers have access have risen sharply. One of the digital tools available for the teaching of mathematics is Mathematics Analysis Software (MAS). It is a term to describe software with which 'user can perform algorithmic processes required when working in one or more branches of mathematics' (Pierce \& Stacey, 2010, p. 2). Furthermore, this technology is described as a cognitive tool that actively engages learning in knowledge construction reflect their comprehension and conception of the information (Herrington \& Parker, 2013). MAS also facilitates the technical dimension of mathematical activities and enable users to manipulate mathematical objects (Pierce \& Stacey, 2010).

However, it is not enough that students and teachers simply have access to digital tools such as MAS since the teacher plays an important role in how this digital technology is used in teaching and learning process. Therefore, the matter is not only teachers' use of digital technology in their mathematics lessons but how they integrate it (McCulloch et al., 2018). According to Comi et al. (2017), the effectiveness of technology at school depends on the actual use that teachers make of it. Furthermore, it is regarded that advantages from technology integration depend on teachers' instructional practices in the classroom.

Various studies around the world have been conducted to describe teachers' digital technology use in the mathematic classroom (e.g., Afshari et al., 2009; Goos \& Bennison, 2008). Furthermore, a range of studies has also been conducted investigating various issues such as teaching approaches (e.g., Pelgrum \& Voogt, 2009) and types of software and hardware being used (Bretscher, 2014; Loong et al., 2011). Furthermore, other studies examined how mathematics teachers use technology regarding the orientation of pedagogy (e.g., Bretscher, 2014; Fraser \& Garofalo, 2015; Hammond et al., 2011; Hollebrands \& Okumuş, 2018; Petras, 2010; Polly, 2014; Tay et al., 2012).

However, regarding studies on teachers' use of MAS in mathematics teaching, a number of studies have been reported (Agyei \& Benning, 2015; Agyei \& Voogt, 2016; Bozkurt \& Ruthven, 2017; Bulut \& Bulut, 2011; Doruk et al., 2013; Zilinskiene \& Demirbilek, 2015). However, the previous studies paid less attention to examine pedagogical activities at three levels of instructional practices as proposed by Pierce and Stacey (2010). Those studies lack of full description of reveal teachers' pedagogical practices in the use of MAS in mathematics teaching. In addition, to the best of our knowledge, there has been no a qualitative study in the context of Indonesia that uses Pierce and Stacey's (2010) pedagogical MAP of MAS to understand secondary mathematics teachers' instructional practices in the use of MAS. 
We investigated the use of MAS as it is has been widely used by mathematician as well as mathematics teachers for teaching and learning of mathematics and has great potential to change teaching and learning of mathematics. Furthermore, for teaching and learning of mathematic setting, MAS may be available as computer software such as spreadsheets, dynamic geometry software and dynamic mathematics software. In addition, this tool may also available as hand held devices such as scientific calculator, graphic calculator, and computer algebra system.

Due to wide availability and great potential of MAS, we believe that the findings of this study fill the gaps and advances our understanding of secondary school teachers' instructional practices when they integrate the digital tool in their mathematics teaching. Therefore, the aim of this study was to investigate secondary school mathematics teachers' use of Mathematical Analysis software in teaching mathematics through the lens of the pedagogical map of MAS (Pierce \& Stacey, 2010) as well as to identify links between task set by the teachers with their instructional practices at subject and classroom levels. Therefore, this study addressed two research questions:

1. To what extent do secondary school mathematics teachers use Mathematics Analysis Software in mathematics teaching?

2. To what extent is the type of tasks set by the teachers related to their instructional practices in using of Mathematics Analysis Software at subject and classroom levels?

\section{LITERATURE REVIEW AND CONCEPTUAL FRAMEWORK}

Previous studies have used various frameworks to investigate the ways of digital technologies is used in teachings, such as student-centred and teacher-centred framework (Bretscher, 2014; Polly, 2014); the Learning with and Learning from framework (e.g., Tay et al., 2012); routine, extended and innovative user (e.g., Hammond et al., 2011). In term of the investigation of digital technology in mathematics teaching, with emphasis on mathematics analysis software, Pierce and Stacey (2010) proposed framework of the pedagogical map, explaining pedagogical opportunities of Mathematics Analysis Software (MAS).

As mentioned earlier, MAS is an umbrella term used to describe software with which users can conduct algorithmic processes when doing one or more topics of mathematics (Pierce \& Stacey, 2010). With this tool, users can carry out calculations of arithmetic and statistics data display, and construction of geometric figures. Many software is available that user can conduct algorithmic process when users working in mathematics. MAS is available as computer software such as Excel, GeoGebra, Geometers Sketchpad, and autograph as well as available as hand held calculators such as scientific calculators, graphic calculators and computer algebra system.

The main feature of Mathematical Analysis Software is that users can use the software to do mathematical algorithms with their own input. It is adaptable software that users specify what it will do. Therefore, not all digital tools for mathematics teaching is MAS. It excludes software for presentation (e.g. PowerPoint) or, courseware or software for communication and drill, and practice (Pierce \& Stacey, 2010).

\section{Mathematics Analysis Software (MAS) As A Cognitive Tool}

According to Jonassen (1996b) a cognitive tool is referred to learning with technology instead of learning through technology. Kim and Reeves (2007) define a cognitive tool as a technology that users can interact and think with in process of knowledge construction. Furthermore, a cognitive tool is a computer software that is intended to facilitate and engage process of cognitive and it is a set of tool that needed by learners to facilitate cognitive apprenticeships (Jonassen, 1996b). A cognitive tool can help learner with critical thinking and complex learning activities and it support learner to control the construction of their knowledge (Jonassen, 1996a). Shim and Li (2006) argue that a cognitive tool can benefit students providing them the following functions: (1) supporting cognitive processes; (2) haring the cognitive load; (3) allowing students to get involved in cognitive activities; and (4) allowing student to engage in problem solving activities through generating and testing hypotheses

MAS is regarded as a cognitive tool that facilitates the technical dimension of mathematical activities (Zbiek et al., 2007). Cognitive tools are technologies that strengthen human being cognitive powers during thinking, problem-solving, and learning (Jonassen \& Reeves, 1996, p. 639). According to Jensen (2011), the human cognitive system can be enhanced through the integration of cognitive tool. Therefore, when cognitive tools are integrated into teaching, the approach should be different from traditional approaches (Wang et al., 2014). By using the cognitive tool, learners should engage in various critical, creative, and complex thinking opportunities (Hsu et al., 2013).

Furthermore, MAS, as a digital tool, can be beneficial as learnier can organize information into a visual and auditory channel (Hillmayr et al., 2020). Furthermore, digital tools allow learners to engage actively with the content of learning in order to understand new information (Mayer, 2014). Interactive learning environments of a digital tool make it possible for learners to actively influence their own learning process (Hillmayr et al., 2020). Therefore, learners can manipulate presented information and interact with learning environments that enable them to act as a sense-makers in constructing their own knowledge (Hillmayr et al., 2020). In addition, an interactive digital tool should support students deep learning through cognitive activities (Mayer, 2014).

\section{Pedagogical Map of Mathematical Analysis Software}

Pierce and Stacey (2010) proposed the pedagogical map of MAS (Figure 1) that is structured at three levels, namely the tasks teacher set for their students; teachers' classroom interaction; and the subject being taught. According to Pierce and Stacey (2010), at the task level, MAS offers five pedagogical opportunities that are 'learn pen and paper skills', 'use real data', 'explore regularity and variation', 'stimulate real situations', and 'link representations'. 


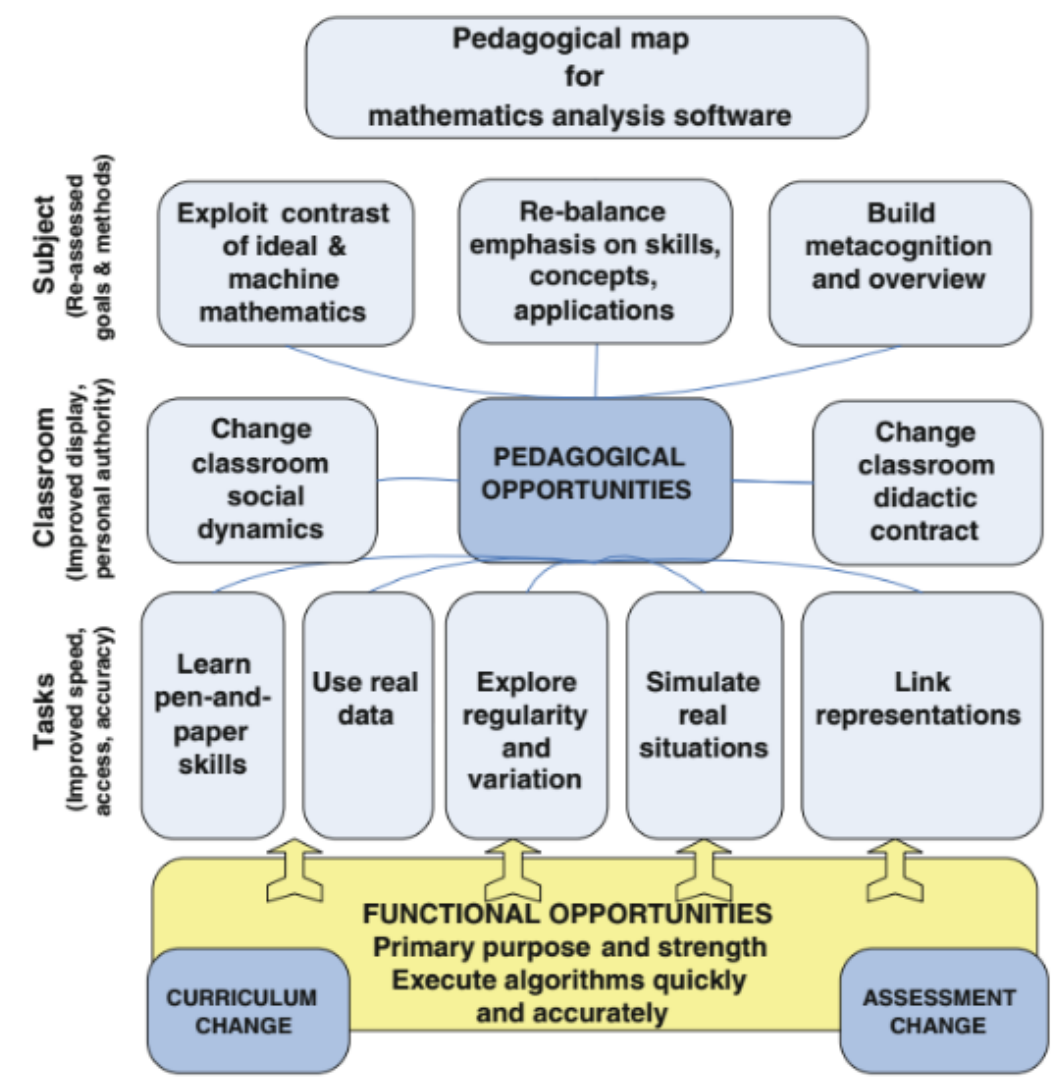

Figure 1. The pedagogical map of MAS (Pierce \& Stacey, 2010)

Table 1. Description of functional and pedagogical opportunities

\begin{tabular}{|c|c|c|}
\hline \multicolumn{2}{|r|}{ Pedagogical opportunities } & Description (Sample of Teachers' Activities) \\
\hline \multirow{5}{*}{ Task Level } & Learn pen-and-paper skills (LPP) & The teacher assigns students to use instant 'answers' as feedback in learning processes \\
\hline & Use real data (RD) & The teacher assigns students to working on real world problems involving calculations \\
\hline & $\begin{array}{l}\text { Explore regularity and variation } \\
\qquad(\mathrm{RV})\end{array}$ & $\begin{array}{c}\text { The teacher assigns students to search for patterns, observe effect of parameters, and use forms } \\
\text { of general formula. }\end{array}$ \\
\hline & Stimulate real sit & $\begin{array}{l}\text { The teacher assigns students to use dynamic diagrams, drag and collect data for analysis, and } \\
\text { generate statistical data sets }\end{array}$ \\
\hline & Link Representation (LR) & $\begin{array}{l}\text { The teacher assigns students to use digital tool to move between numeric, graphic, and symbolic } \\
\text { representations. }\end{array}$ \\
\hline \multirow{2}{*}{$\begin{array}{l}\text { Classroom } \\
\text { Level }\end{array}$} & $\begin{array}{l}\text { Change classroom social dynamic } \\
\text { (CCSD) }\end{array}$ & $\begin{array}{l}\text { The teacher facilitates rather than dictates, encourages group, and encourages students to } \\
\text { initiate discussion and share their learning }\end{array}$ \\
\hline & $\begin{array}{l}\text { Change classroom didactic } \\
\text { contract (CCDC) }\end{array}$ & $\begin{array}{r}\text { The teacher allows MAS to become a new authority, chang } \\
\text { teachers, and permits explosion of a }\end{array}$ \\
\hline \multirow{3}{*}{$\begin{array}{l}\text { Subject } \\
\text { Level }\end{array}$} & $\begin{array}{l}\text { Exploit contrast of ideal and } \\
\text { machine mathematics (EIMM) }\end{array}$ & $\begin{array}{l}\text { The teacher intentionally uses unexpected error messages, expressions, graphical displays as } \\
\text { catalysts for discussion }\end{array}$ \\
\hline & $\begin{array}{l}\text { Rebalance emphasis on skills, } \\
\text { concepts, applications (RSCA) }\end{array}$ & $\begin{array}{l}\text { The teacher adjusts goals of teaching, spends less time on routine skills, more time on } \\
\text { understanding of concepts and applications, and increases emphasis on mathematical thinking. }\end{array}$ \\
\hline & $\begin{array}{l}\text { Build metacognition and overview } \\
\text { (BMO) }\end{array}$ & $\begin{array}{c}\text { The teacher gives an overview as introduction, links concepts through manipulation of symbolic } \\
\text { expressions, and uses of multiple representations. }\end{array}$ \\
\hline
\end{tabular}

Furthermore, the classroom level has two pedagogical opportunities, namely change of classroom social dynamic and change of classroom didactic contract. In the classroom, MAS introduces as a new authority other than the teacher (Pierce \& Stacey, 2010). As results, teachers and students my change their expectations. Furthermore, the use of MAS may encourage students to take control over their learning which results a change of didactic contract (Pierce \& Stacey, 2010). According to Brousseau (1997), didactic contract is 'a system of rules, mostly implicit, associating the students and the teacher, for a given piece of knowledge' (p. 15). Teacher crate situation in which can provide to student aspects of mathematics such as the use of interest of mathematics. With the use of MAS, this situation might change as students also can provide such aspects.

At the subject level, MAS provides opportunities for rebalancing emphasis on skills, concepts, and applications, and building metacognition and overview, as well as exploiting the contrast between ideal and machine mathematics. Based on the pedagogical map of MAS, we present a framework of this study in terms of teachers' activities at each level of their instructional practices in Table 1. 
Table 2. Demographic Information of Participants

\begin{tabular}{cccc}
\hline Participants & Gender & Teaching Experience & Level of Education \\
\hline Ina & $\mathrm{F}$ & 1 Year & Undergraduate degree \\
\hline Mirna & $\mathrm{F}$ & 2 Years & Undergraduate degree \\
\hline Lila & $\mathrm{F}$ & 13 Years & Undergraduate degree \\
\hline Yudin & $\mathrm{M}$ & 20 Years & Undergraduate degree \\
\hline Alfi & $\mathrm{M}$ & 8 Years & Undergraduate degree \\
\hline Tia & $\mathrm{F}$ & 17 Years & Post-Graduate degree \\
\hline Aan & $\mathrm{M}$ & 10 Years & Post-Graduate degree \\
\hline Rahman & $\mathrm{M}$ & 11 Years & Post-Graduate degree \\
\hline Erli & $\mathrm{F}$ & 4 Years & Post-Graduate degree \\
\hline Ary & $\mathrm{M}$ & 14 Years & Post-Graduate degree
\end{tabular}

\section{METHODS}

\section{Research Design}

In this study, we employed a case study approach to examine mathematics teacher instructional practices when they use MAS in mathematics teaching (Merriam \& Tisdell, 2015). According to (Merriam \& Tisdell, 2015), a qualitative case study is a holistic description of a bounded phenomenon such as a person or a process. The data of the present study were collected from a bounded phenomenon, which is mathematics teachers who have experiences in using of Mathematics Analysis Software in their classrooms. The cases were selected to understand the phenomena of teachers' MAS integration according to the three levels of pedagogical opportunities.

\section{Participants}

To recruit the participants, we distributed a questionnaire asking the participants whether they have used Mathematical Analysis Software in their classrooms and were willing to participate in this study. Accordingly, fourty teachers were willing to take part. Furthermore, we referred to Guest et al. (2006) in determining the number of participants. They suggest that 12 participants are adequate sample size for qualitative research. Therefore, we selected 12 out of the 40 participants. However, two participants did not satisfy the criteria of this study because when we observed in their teaching, they used PowerPoint instead of MAS. Therefore, only ten participants were analysed, as shown in Table 2. Anonymity of participants was ensured; therefore, their real names did not appear.

\section{Research Instrument}

As previously mentioned, Pierce and Stacey's (2010) pedagogical map were adapted as a framework to investigate teachers' instructional practice in the use of Mathematic Analysis Software. Therefore, the classroom observations and semi-structured interview focused on teachers' instructional practices at the subject level, classroom level, and task level. We used the observation sheet for documenting important data in terms of the three aspects of the instructional practices. Furthermore, we used an interview protocol related to the three levels of teacher instructional practices.

\section{Reliability and Validity}

According to (Creswell, 2007), triangulation, which different sources and methods are used, is one of the strategies to validate a qualitative study. In the present study, we carried out triangulation involving data from classroom observations and semistructured interviews to strengthen the trustworthiness of the study. Furthermore, in a qualitative study, reliability refers to the stability of responses to multiple coders of a data set (Creswell, 2007). Therefore, in the present study, we developed a codebook of code to enhance reliability.

A codebook is defined as set of codes, definitions, and examples that is utilized as a guide in analysis of interview data. It is necessary in analysing of interview data since it provide operationalization of the coded (Fonteyn et al., 2008). In this study, we used theory driven coded that involving three steps as proposed by (Boyatzis, 1998). The steps are included: (1) generating the code; (2) reviewing and revising the conde; and (3) determining the reliability of coders and the codes.

\section{Procedure for Data Collection}

As discussed previously, data were collected through classroom observations and semi-structured interview. Twelve participants participate in the classroom observations and interviews. We observed one lesson for each participant which took 60-90 minutes. The participants were free to decide on what topic they would like to teacher according to their teaching schedules. To ensure we captured all the classroom activities, we video all the observed classes. We observed various lesson as shown in Table 3. 
Table 3. Topics of Mathematics being observed

\begin{tabular}{cc}
\hline Participants & Topics being observed \\
\hline Ina & Translation \\
\hline Mirna & Reflection \\
\hline Lila & Reflection \\
\hline Yudin & Circle \\
\hline Alfi & Three-dimensional geometry \\
\hline Tia & Translation \\
\hline Aan & Graphs of trigonometric functions \\
\hline Rahman & Differential calculus \\
\hline Erli & Inverse functions \\
\hline Ary & Reflection
\end{tabular}

Classroom observations were followed up with semi structured interviews. We allowed participants to decided time and places for the interviews. As a result, all participants would like to be interviewed right after the observations. We interviewed nine participants in their offices while one participant was interviewed in a school park. It took about 30-40 minutes of the interview and we audiotaped all the participants.

\section{Data Analysis}

In a qualitative study, the researcher can employ both deductive and inductive approaches in analysing the data (Azungah, 2018; Burnard et al., 2008). The deductive approach uses an organising framework consisting of themes for coding process, while the inductive approach involves data that drive analysis entirely (Bradley et al., 2007). In this study, we employed a deductive qualitative analysis approach to analyse classroom observation and interview data by using an existing framework, that is the Pedagogical Map of MAS (Pierce \& Stacey, 2010). Furthermore, we carried out data triangulation resulting from classroom observations and interviews.

\section{RESULTS}

In this section, we describe teachers' instructional practices in the use of MAS regarding the conceptual framework. It is important to highlight that we present teachers' instructional practices according to data of classroom observations and semistructured interviews. Therefore, only activities that were appeared in the observations and revealed in the interviews were regarded as teachers' instructional practices. Furthermore, we identified patterns of teachers' instructional practice at classroom and subject levels according to the type of tasks they set for the students.

\section{Teachers' Instructional Practices}

\section{Task level}

The framework of MAS offers five types of tasks that teachers can set for students when they use MAS in mathematics teaching. The tasks namely 'learn pen-and-paper skills', 'explore regularity and variation', 'link representation', 'simulate real situations' and 'use real data'. This study showed that the participants had provided different type of tasks to their students, and some of the teacher assigned two more type of tasks in one lesson.

Five participants (Ina, Mirna, Aan, Ary and Alfi) provided two types of tasks in one lesson. For example, Aan assigned his students to use a slider on Autograph to investigate the parameter of ' $A$ ' of trigonometric functions $Y=A \sin X$ and $Y=A$ Cos $X$. Furthermore, students were assigned to observe changes in the graphs when the parameter was changed. Aan also assigned students to observe the parameter of " $A$ " and " $B$ " for the function of $Y=\operatorname{Sin} A X+B$ and $Y=\operatorname{Cos} A X+B$. At the end of the lesson, Aan assigned students to draw a conclusion about the parameters. It revealed that Aan provided tasks that encourage his students to use MAS in exploring regularity and variation, and then making conjectures before proceeding to formal proof.

Five participants (Erli, Tia, Rahman, Lila and Yudin) offered on one type of task. Four (Erli, Tia, Rahman and Lila) of them set the 'learn pen-and-paper skill' task. For example, Tia asked students to check their solutions of translation problems by using GeoGebra. Another teacher who provided one type of tasks was Yudin. His students were assigned to use GeoGebra to plot and move circles. Furthermore, the students observed the objects and their properties

Drawing on classroom observation and the interview data, we conclude that 'learn pen-and-paper skills' task, 'explore regularity and variation', and 'link representation' were three most frequently set task by the participants when they integrate MAS in their lessons. However, the findings show that no participant who set tasks of using real data and stimulate real situation. Table 4 is the summary of the participants' use of MAS at the task level. 
Table 4. Summary of participants' use of MAS at the task level

\begin{tabular}{cc}
\hline Participants & Participants' Instructional Practices \\
\hline Ina & RV and LR \\
\hline Mirna & RV and LR \\
\hline Lila & LPP \\
\hline Yudin & LR \\
\hline Alfi & LPP and RV \\
\hline Tia & LPP \\
\hline Aan & RV and LR \\
\hline Rahman & LPP \\
\hline Erli & LPP \\
\hline Ary & RV and LR \\
\hline
\end{tabular}

Table 5. Summary of participants' use of MAS at the classroom level

\begin{tabular}{cc}
\hline Participants & Participants' Instructional Practices \\
\hline Ina & CCSD and CCDC \\
\hline Mirna & CCSD \\
\hline Lila & CCSD \\
\hline Yudin & - \\
\hline Alfi & - \\
\hline Tia & - \\
\hline Aan & CCSD and CCDC \\
\hline Rahman & CCSD \\
\hline Erli & - \\
\hline Ary & CCSD \\
\hline
\end{tabular}

\section{Classroom level}

At the classroom level, we focused on the change of cognitive and social aspects, namely "change classroom didactic contract" and "change classroom social dynamics. Regarding "change classroom didactic contract", It showed that three participants (Ina, Aan and Ary) indicated they use MAS in ways that this digital technology was as a new 'authority' other than the teacher. Their students were assigned to use MAS to carry put their mathematical explorations and to share their findings to the teacher and the rest of the class. For example, Aan used the discovery-learning method with various activities such as discussions and completing the tasks. He assigned the students four tasks and worked in groups with the help of MAS. In Aan's lesson, the didactic contract was changed where students provided their own explanations and discovered their own generalisations rather than relying on the teacher. Furthermore, students shared their findings to other students and explained their reasons. Furthermore, the social dynamic was also changed since students worked collaboratively and discussed in groups.

In terms of classroom social dynamic, the results showed that six teachers (Ina, Mirna, Aan, Ary, Rahman and Lila) had changed their classroom dynamics when they integrated MAS in their lessons. For example, Lila used dynamic mathematics software to teach the concept of reflection. Students were assigned to work in a group of four students to four problems, one of them was to find the reflection of $x^{\wedge} 2+y^{\wedge} 2-4 x+2 y-4=0^{\wedge}$ in $y=x$. Furthermore, each group was assigned to present solutions to the problems to other groups, while the other groups checked the presented solutions with GeoGebra. The classroom dynamics were changed when students used MAS and worked in groups. In the interview, one of the participants, Ina revealed that:

"The interaction between students and me and interaction between students and students were improved, and I liked it because two-way communication took place in the classroom; there were questions and answers, discussion among and between students. In the observed class, I was not satisfied because there was one group that had too many students. Normally, I assigned students to work in a group of two students in order to minimise the number of students who are inactive. Thus, students discussed in pairs.'

It is shown that at the classroom level, Ina took advantage of the pedagogical opportunities of MAS to change her classroom social dynamics. Table 5 summarises findings of participants' use of MAS at the classroom level. It shows that, at the classroom level, more than half of the participant has successfully changed their classroom social dynamic when MAS was integrated into their lessons. Nevertheless, the majority of classroom didactic contract remained the same since only two participants who indicated the change of this aspect when they integrated the digital tools.

\section{Subject level}

Regarding subject-level opportunities, three opportunities offered by MAS are building metacognition and overview; rebalancing emphasis on skills, concepts, and applications; and exploiting the contrast between ideal and machine mathematics. Therefore, we present the results based on those themes.

It was revealed that there were three participants (Ina, Mirna and Ary) who built metacognition and overview of mathematics topics in their mathematics teaching. They started their lessons with overviews of the real-world context instead of with details of mathematical concepts. Ary, for instance, in the observed class, started his lesson by inserting a picture of a butterfly into Dynamic Geometry Software and showing his students the 'reflection' of the butterfly. 
Table 6. Summary of participants use MAS at the subject level

\begin{tabular}{cc}
\hline Participants & Participants' Instructional Practices \\
\hline Ina & RSCA and BMO \\
\hline Mirna & RSCA and BMO \\
\hline Lila & - \\
\hline Yudin & - \\
\hline Alfi & - \\
\hline Tia & - \\
\hline Aan & RSCA \\
\hline Rahman & - \\
\hline Erli & - \\
\hline Ary & RSCA, and BMO
\end{tabular}

Table 7. Pattern of participants' instructional practices

\begin{tabular}{cccc}
\hline Participants & Task Level & Classroom Level & Subject Level \\
\hline Ina & RV and LR & CCSD and CCDC & RSCA and BMO \\
\hline Mirna & RV and LR & CCSD & RSCA and BMO \\
\hline Aan & RV and LR & CCSD and CCDC & RSCA \\
\hline Ary & RV and LR & CCSD & RSCA, and BMO \\
\hline Alfi & LPP and RV & - & - \\
\hline Lila & LPP & CCSD & - \\
\hline Rahman & LPP & CCSD & - \\
\hline Tia & LPP & - & - \\
\hline Erli & LPP & - & \\
\hline Yudin & LR & - \\
\hline
\end{tabular}

Those three participants indicated that the use of MAS had changed their approach to mathematics topics. One of the participants revealed that:

"By using technology, it changed my approach to teaching. For example, in the classroom, I first gave students problems to be solved by using the tool, and then, through solving the problems, students discovered the concepts of a topic in mathematics."

Mirna started the lesson by solving problems instead of solving problems at and the end of the lesson as presented in the textbook. After working on the problems, the teacher and students then revisited formal mathematical concepts through the teacher's exposition. However, most of the participants did not change their approach to mathematics topics when they used MAS in the classroom. Also, they did not take advantage of this tool to encourage students to build metacognition and an overview of mathematics topics.

Regarding exploit contrast between ideal and machine mathematics, when teachers use MAS they may deliberately take advantage of the constraints the technology to provoke students' mathematical thinking. However, in the observations and the interviews, it was revealed that there was no participant who exploited the contrast between ideal and machine mathematics.

As described in the pedagogical map of MAS, rebalance emphasis on skill, concepts, and applications is another pedagogical opportunity offered by the tool. The result of classroom observation and interview revealed that four participants (Ina, Mirna, Aan and Ary) spent time in their teaching to present applications of mathematics concepts. Ina, for instance, used 20 minutes of her time for presenting applications of translation in real-life. In the interview, one of the participants said that:

"Applications of mathematics concepts should be emphasised when students use ICT in the classroom, it is not a trial and error activity but without understanding what students are doing. For example, when I taught the topic of reflection, students used GeoGebra to reflect a picture of a cat in Y-axis, thus, students found that the result of the reflections was not changed, if they reflected a picture of a cat, the result was still a cat; therefore, students learned concepts of reflection that reflection does not change the shape of an object."

Finally, Table 6 highlights the participants use of MA at subject level.

In summary, the findings of this study showed that the teachers integrated MAS for various activities and purposes in their mathematics lessons. Regarding teachers' instructional practices at the task level, the findings showed that 'learn pen -and- paper skill', 'link representation', and 'explore regularity and variation', were most dominant tasks set by the teachers. However, at the subject level, the majority of the teachers did not rebalance emphasis on skills, concepts and application of mathematics, and did not change their approaches to mathematical contents. Furthermore, only a small number of the participants changed their didactic contracts.

\section{Links of Teachers' Instructional Practices}

To better understand teachers' instructional practices, we identified the pattern of teachers' instructional practice in the use of MAS across the different levels. To identify the pattern, we summarise of teachers' instructional practices at each level in Table 5. As shown in the table, teachers' classroom practices at the task level have linked to subject level and classroom level. 
There were two important findings that we identified in Table 7. First, participants who set both explore regularity and variation and link representation tasks appeared to change their classroom practices at classroom and subject levels. Their classroom social dynamic and didactic contracts were changed. They also changed their approaches to mathematics topic by rebalancing emphasis on skills, concepts, and application as well as building metacognition and overview. Second, the table shows that participants who set type tasks of learn pen and paper skill tend to keep the existing practices. Most of them did not take advantage of pedagogical opportunities of MA at subject and classroom level. Based on the pattern, we can conclude the types of tasks set by the teachers have a relationship with the teachers' classroom practice in using MAS at subject and classroom levels.

\section{DISCUSSIONS}

This study aimed to examine secondary school mathematics teachers use of Mathematics Analysis Software (MAS) through the lens of the pedagogical map of MAS (Pierce \& Stacey, 2010) Also this study identify relationship between type task set by teacher and their classroom practices at subject and classroom levels. The findings of this study show several important points of discussion.

First, at the classroom level, this study suggested that most of the participants did not take advantage of MAS to facilitate changes in didactic contracts. Literature reveals that MAS plays an important role in didactic contract that mediates both individual and collaborative learning (Pierce \& Stacey, 2010). The main players in didactic contract are teachers, students, and knowledge (Bolondi et al., 2018). These three main players are regarded as the didactic triangle. However, the advent of technology has expanded this triangle to a didactical tetrahedron containing technology (Ruthven, 2012). However, the finding of this study shows that, to large extent, the use of MAS has not expended the didactic contract. However, in term of classroom social dynamic, this study shows that the use of MAS, to some extent, has changed classroom interaction.

Second, at the task level, most of the participants still valued MAS as a tool for students' drill and practices by providing paperand-pen skills' tasks for their students. They assigned this type of tasks more frequently than other types of tasks. As a result, most of the participants still did provide rich mathematical tasks when they integrated MAS in their teaching. Unfortunately, according to Cavanagh and Mitchelmore (2011), drill and practice tasks do not significantly affect students' learning achievements since this type of task is similar to rote learning exercises. Furthermore, drill-and-practice was seen as an example of the traditional use of technology in education (Kuiper \& de Pater-Sneep, 2014). However, the finding of this study is consistent with previous studies that although drill and practice may not be seen as innovative use of technology, it still is much used (Ertmer \& Park, 2009; Inan et al., 2010).

Third, in terms of teachers' use of MAS at the subject level, the finding suggests that most of the participant still used a traditional method to approach mathematics topics. This finding indicates that they did not take advantage of MAS for building of metacognition and overview of mathematics topics. According to (Tzohar-Rozen \& Kramarski, 2017), the metacognition skill helps learners to increase their understanding and comprehension ability. Also, it helps learners to understand and to learn in an effective manner that makes them easy to acquire new habits of thinking (Tzohar-Rozen \& Kramarski, 2017). Additionally, the use of MAS such as Computer Algebra System can encourage metacognition and overview. Furthermore, the finding showed that most of the participants did not use the digital tool to alter the balance in teaching between skills, concepts, and applications while existing literature has exposed that technology offers this pedagogical opportunity.

Fourth, the link between types of the tasks set by the teacher and their instructional practice at classroom and subject levels was revealed. Teachers who set a constructivism-oriented task such as explore regularity and variation tended to change their practice at classroom and subject level. In addition, the explore regularity and variation is one of the types of rich mathematical tasks since it suits within exploratory and investigative context (Foster, 2013). Furthermore, rich tasks that involve exploration and related to real-world application and context may require teachers to adopt new approaches to teaching (Aubusson et al., 2014). This is one of the possible reasons that participants of this study who set such the tasks tended to change their instructional practices and classroom and subject level. On the other hand, participants who set behaviourism-oriented tasks such as learn paper and pen skills seem to keep their existing practice when they integrated the digital tool in their lessons.

It can be concluded that, to a large extent, the participants failed to fully take advantage of pedagogical opportunities offered by Mathematics Analysis Software. One of possible reasons of this unfavourable state is that Indonesia secondary mathematic teachers had lack of knowledge of ICT as well as lack of knowledge of the integration of the technology in the classroom (Mailizar \& Fan, 2019). Such knowledge is necessary acquired by teachers in order to able to integrate technology in ways that bring realworld experience into the classroom as well as provide scaffolding to facilitate students learning in complex cognitive tasks (Baek et al., 2008).

As a cognitive tool, MAS should be able to facilitate the knowledge construction process. Moreover, cognitive tools can serve as facilitators of learning by reducing cognitive overload and increasing high-level cognitive process (Liu et al., 2013). Finally, the finding of this study suggests that one of the important steps that teachers need to do in order to be able to fully capitalize MAS in their teaching is to design rich mathematical tasks with which lead to a change in teachers' instructional practice at classroom and subject levels. Technology-rich mathematical tasks address higher-order thinking skills and utilize technology to simulate, represent and model mathematical contents. As a result, this type of tasks offer students opportunities to propose and test conjectures and communicate mathematics ideas (Polly \& Hannafin, 2010). Technology-rich mathematical tasks that is necessary since students who engage in such tasks have significantly outperformed their peers on assessment of mathematics (Polly, 2008). 


\section{CONCLUSIONS}

The finding of this study suggested that the participants did not fully take advantage of mathematics analysis software to enhance their mathematics teaching and failed the value MAS as a tool to facilitate student knowledge construction. Furthermore, this study showed that there were links between the type of tasks and teachers' instructional practices at subject and classroom levels when they integrated MAS in their lessons. However, this study is subject to two limitations. First, classroom observations were carried out only once for each participant. Second, the lessons being observed were not focused on one topic of mathematics, such as geometry or algebra. These two limitations may cause this study less depth in exploring the issue being studied. Therefore, for further studies, we proposed the following two directions. First, it would be meaningful to conduct similar studies with a specific focus on topics of mathematics such as geometry. Second, as this study had revealed that types of tasks are very important in order to change teachers' pedagogical at classroom and subject levels when they integrated MAS in their lessons, it is necessary to conduct a study to understand and develop teachers' knowledge in designing technology rich-mathematics tasks in order to assist them to be able to fully take advantages of pedagogical opportunities offered by Mathematics Analysis Software.

\section{ACKNOWLEDGEMENT}

We would like to thank Asian Centre for Mathematics Education, East China Normal University for financially support the completion of this paper by a research grant (Project No. 92900-120215-10514). The second author's participation was also in part supported by a research grant from East China Normal University's "Happy Flowers" Strategic Research Fund (Award No: 2019ECNU-XF2H004). We also wish to thank Sophie Li and Fadhilah for their assistance at the final stage of the completion of the paper.

\section{REFERENCES}

Afshari, M., Bakar, K. A., Luan, W. S., Samah, B. A., \& Fooi, F. S. (2009). Factors affecting teachers' use of information and communication technology. Online Submission, 2(1), 77-104.

Agyei, D. D., \& Benning, I. (2015). Pre-service teachers' use and perceptions of GeoGebra software as an instructional tool in teaching mathematics. Journal of Educational Development and Practice, 5(1), 14-30.

Agyei, D. D., \& Voogt, J. M. (2016). Pre-service mathematics teachers' learning and teaching of activity-based lessons supported with spreadsheets. Technology, Pedagogy and Education, 25(1), 39-59. https://doi.org/10.1080/1475939x.2014.928648

Aubusson, P., Burke, P., Schuck, S., Kearney, M., \& Frischknecht, B. (2014). Teachers choosing rich tasks: The moderating impact of technology on student learning, enjoyment, and preparation. Educational Researcher, 43(5), $219-229$. https://doi.org/10.3102/0013189x14537115

Azungah, T. (2018). Qualitative research: deductive and inductive approaches to data analysis. Qualitative Research Journal, 18(4), 383-400. https://doi.org/10.1108/QRJ-D-18-00035

Baek, Y., Jung, J., \& Kim, B. (2008). What makes teachers use technology in the classroom? Exploring the factors affecting facilitation of technology with a Korean sample. Computers \& Education, 50(1), $224-234$. https://doi.org/10.1016/j.compedu.2006.05.002

Bolondi, G., Ferretti, F., \& Giberti, C. (2018). Didactic Contract as a Key to Interpreting Gender Differences in Maths. Journal of Educational, Cultural and Psychological Studies (ECPS Journal), (18), 415-435. https://doi.org/10.7358/ecps-2018-018-bolo

Boyatzis, R. E. (1998). Transforming qualitative information: Thematic analysis and code development. Sage.

Bozkurt, G., \& Ruthven, K. (2017). Classroom-based professional expertise: A mathematics teacher's practice with technology. Educational Studies in Mathematics, 94(3), 309-328. https://doi.org/10.1007/s10649-016-9732-5

Bradley, E. H., Curry, L. A., \& Devers, K. J. (2007). Qualitative data analysis for health services research: developing taxonomy, themes, and theory. Health services research, 42(4), 1758-1772. https://doi.org/10.1111/j.1475-6773.2006.00684.x

Bretscher, N. (2014). Exploring the quantitative and qualitative gap between expectation and implementation: A survey of English mathematics teacher' use of ICT. In A. Clark-Wilson, O. Robutti, \& N. Siclair (Eds.), The mathematics teacher in the digital era. Springer. https://doi.org/10.1007/978-94-007-4638-1_3

Brousseau, G. (1997). Theory of Didactical Situations in Mathematics 1970-1990 (Vol. 19). Kluwer.

Bulut, M., \& Bulut, N. (2011). Pre Service Teachers' Usage of Dynamic Mathematics Software. Turkish Online Journal of Educational Technology-TOJET, 10(4), 294-299.

Burnard, P., Gill, P., Stewart, K., Treasure, E., \& Chadwick, B. (2008). Analysing and presenting qualitative data. British dental journal, 204(8), 429. https://doi.org/10.1038/sj.bdj.2008.292

Cavanagh, M., \& Mitchelmore, M. (2011). Learning to teach secondary mathematics using an online learning system. Math Ed Res J, 23, 417-435. https://doi.org/10.1007/s13394-011-0024-1

Comi, S. A., Argentin, G., Gui, M., Origo, F., \& Pagani, L. (2017). Is it the way they use it? Teachers, ICT and student achievement. Economics of Education Review, 56, 24-39. https://doi.org/10.2139/ssrn.2795207 
Creswell, J. W. (2007). Qualitative inquiry and research design: choosing among five approaches. Sage.

Doruk, B. K., Aktümen, M., \& Aytekin, C. (2013). Pre-service elementary mathematics teachers' opinions about using GeoGebra in mathematics education with reference to 'teaching practices'. Teaching Mathematics and its Applications: An International Journal of the IMA, 32(3), 140-157. https://doi.org/10.1093/teamat/hrt009

Ertmer, P. A., \& Park, S. H. (2009). Changing teachers' beliefs toward classroom technology use: The potential of problem-based learning. EARLI Conference.

Fonteyn, M. E., Vettese, M., Lancaster, D. R., \& Bauer-Wu, S. (2008). Developing a codebook to guide content analysis of expressive writing transcripts. Applied Nursing Research, 21(3), 165-168. https://doi.org/10.1016/j.apnr.2006.08.005

Foster, C. (2013). Mathematical études: Embedding opportunities for developing procedural fluency within rich mathematical contexts. International Journal of Mathematical Education in Science and Technology, 44(5), 765-774. https://doi.org/10.1080/0020739x.2013.770089

Fraser, \& Garofalo, J. (2015). Novice mathematics teacher' use of technology to enhance student engagement, questioning, generalization, and conceptual understanding. Journal of Technology and Teacher Education, 23(1), 29-51.

Goos, M., \& Bennison, A. (2008). Surveying the technology landscape: Teachers' use of technology in secondary mathematics classrooms. Mathematics Education Research Journal, 20(3), 102-130. https://doi.org/10.1007/bf03217532

Guest, G., Bunce, A., \& Johnson, L. (2006). How many interviews are enough? An experiment with data saturation and variability. Field Methods, 18(1), 59-82. https://doi.org/10.1177/1525822X05279903

Hammond, M., Reynolds, L., \& Ingram, J. (2011). How and why do student teachers use ICT? Juornal of Computer Assisted Learning, 27, 191-203. https://doi.org/10.1111/j.1365-2729.2010.00389.x

Herrington, J., \& Parker, J. (2013). Emerging technologies as cognitive tools for authentic learning. British Journal of Educational Technology, 44(4), 607-615. https://doi.org/10.1111/bjet.12048

Hillmayr, D., Ziernwald, L., Reinhold, F., Hofer, S. I., \& Reiss, K. M. (2020). The potential of digital tools to enhance mathematics and science learning in secondary schools: A context-specific meta-analysis. Computers \& Education, 103897. https://doi.org/10.1016/j.compedu.2020.103897

Hollebrands, K., \& Okumuş, S. (2018). Secondary mathematics teachers' instrumental integration in technology-rich geometry classrooms. The Journal of Mathematical Behavior, 49, 82-94. https://doi.org/10.1016/j.jmathb.2017.10.003

Hsu, H.-Y., Wang, S.-K., \& Runco, L. (2013). Middle school science teachers' confidence and pedagogical practice of new literacies. Journal of science education and technology, 22(3), 314-324. https://doi.org/10.1007/s10956-012-9395-7

Inan, F. A., Lowther, D. L., Ross, S. M., \& Strahl, D. (2010). Pattern of classroom activities during students' use of computers: Relations between instructional strategies and computer applications. Teaching and Teacher Education, 26(3), 540-546. https://doi.org/10.1016/j.tate.2009.06.017

Jensen, M. (2011). Learning about environmental issues with the aid of cognitive tools. Environment and Natural Resources Research, 1(1), 92. https://doi.org/10.5539/enrr.v1n1p92

Jonassen, D. H. (1996a). Computers in the classroom: Mindtools for critical thinking. Prentice-Hall, Inc.

Jonassen, D. H. (1996b). Learning with technology: Using computers as cognitive tools. In D. Jonassen (Ed.), Handbook of research for educational communications and technology (Vol. 1, pp. 693-719). Macmillan.

Jonassen, D., \& Reeves, T. (1996). Learning with technology: Using computers as cognitive tools. In D. Jonassen (Ed.), Handbook of research for educational communications and technology (pp. 693-719). Macmillan.

Jonassen, D., Peck, K., \& Wilson, B. (1999). Learning with technology: A constructivist perspective. Merrill.

Kim, B., \& Reeves, T. C. (2007). Reframing research on learning with technology: In search of the meaning of cognitive tools. Instructional science, 35(3), 207-256. https://doi.org/10.1007/s11251-006-9005-2

Kuiper, E., \& de Pater-Sneep, M. (2014). Student perceptions of drill-and-practice mathematics software in primary education. Mathematics Education Research Journal, 26(2), 215-236. https://doi.org/10.1007/s13394-013-0088-1

Liu, M., Yuen, T. T., Horton, L., Lee, J., Toprac, P., \& Bogard, T. (2013). Designing technology-enriched cognitive tools to support young learners' problem solving. The International Journal of Cognitive Technology, 18(1), 14-21.

Loong, E., Doig, B., \& Grove, S. (2011). How different is it really? - rural and urban primary students' use of ICT in mathematics. Mathematics Education Research Journal, 23, 189-211. https://doi.org/10.1007/s13394-011-0011-6

Mailizar, M., \& Fan, L. (2019). Indonesian teachers' knowledge of ICT and the use of ICT in secondary mathematics teaching. Eurasia Journal of Mathematics, Science and Technology Education, 16(1), em1799. https://doi.org/10.29333/ejmste/110352

Mayer, R. E. (2014). Cognitive theory of multimedia learning. In R. E. Mayer (Ed.), The Cambridge handbook of multimedia learning (Vol. 2nd, pp. 31-48). Cambridge University Press.

McCulloch, A. W., Hollebrands, K., Lee, H., Harrison, T., \& Mutlu, A. (2018). Factors that influence secondary mathematics teachers' integration of technology in mathematics lessons. Computers \& Education, 123, 26-40. https://doi.org/10.1016/j.compedu.2018.04.008

Merriam, S. B., \& Tisdell, E. J. (2015). Qualitative research: A guide to design and implementation. John Wiley \& Sons.

Pelgrum, W. J., \& Voogt, J. (2009). School and teacher factors associated with frequency of ICT use by mathematics teachers: Country comparisons Education and Information Technologies, 14, 293-308. https://doi.org/10.1007/s10639-009-9093-0 
Petras, C. M. (2010). A descriptive study of science and mathematics teachers pedagogy, ICT use and perceptions of how ICT impacts their teaching Perperdine University]. Malibu, CA.

Pierce, R., \& Stacey, K. (2010). Mapping pedagogical oportunities provide by mathematics analysis software. international Journal Computer Mathematics Learning, 15, 1-20. https://doi.org/10.1007/s10758-010-9158-6

Polly, D. (2008). Modeling the influence of calculator use and teacher effects on first grade students' mathematics achievement. Journal of Computers in Mathematics and Science Teaching, 27(3), 245-263.

Polly, D. (2014). Elementary school teachers' use of technology during mathematics teaching. computers in the Schools, 31, 271292. https://doi.org/10.1080/07380569.2014.969079

Polly, D., \& Hannafin, M. J. (2010). Reexamining technology's role in learner-centered professional development. Educational Technology Research and Development, 58(5), 557-571. https://doi.org/10.1007/s11423-009-9146-5

Ruthven, K. (2012). The didactical tetrahedron as a heuristic for analysing the incorporation of digital technologies into classroom practice in support of investigative approaches to teaching mathematics. ZDM, 44(5), 627-640. https://doi.org/10.1007/s11858011-0376-8

Shim, J., \& Li, Y. (2006). Applications of cognitive tools in the classroom. Emerging perspectives on learning, teaching, and technology. Retrieved from http://projects.coe.uga.edu/epltt

Tay, L. Y., Lim, S. K., Lim, C. P., \& Koh, J. H. L. (2012). Pedagogical approaches for ICT integration into primary english and mathematics: A singapore case study. Australasian Journal of Educational Technology, 28(4), 740-754. https://doi.org/10.14742/ajet.838

Tzohar-Rozen, M., \& Kramarski, B. (2017). Meta-cognition and meta-affect in young students: does it make a difference on mathematical problem solving. Teachers College Record, 119(13), 1.

Wang, S.-K., Hsu, H.-Y., Reeves, T. C., \& Coster, D. C. (2014). Professional development to enhance teachers' practices in using information and communication technologies (ICTs) as cognitive tools: Lessons learned from a design-based research study. Computers \& Education, 79, 101-115. https://doi.org/10.1016/j.compedu.2014.07.006

Zbiek, R. M., Heid, M. K., \& Dick, T. P. (2007). Research on technology in mathematics education: A perspective of construct. In F. K. Lester Jr (Ed.), Second handbook of research on mathematics teaching and learning: A project of the National Council of Teacher of Mathematics. Information Age Publisher.

Zilinskiene, I., \& Demirbilek, M. (2015). Use of GeoGebra in primary math education in Lithuania: an exploratory study from teachers' perspective. Informatics in Education, 14(1), 127. https://doi.org/10.15388/infedu.2015.08 